\title{
Research to Encourage Exercise for Fibromyalgia (REEF): Use of Motivational Interviewing Design and Method
}

\author{
Dennis C. Ang, MD, MS ${ }^{1}$, Anthony S. Kaleth, $\mathrm{PhD}^{2}$, Silvia Bigatti, $\mathrm{PhD}^{3}$, Steve Mazzuca, \\ PhD $^{1}$, Chandan Saha, PhD ${ }^{4}$, Janna Hilligoss, LPN ${ }^{1}$, Mimi Lengerich, BA ${ }^{1}$, and Robert \\ Bandy, MA ${ }^{4}$ \\ ${ }^{1}$ Division of Rheumatology, Department of Medicine, Indiana University \\ ${ }^{2}$ Department of Physical Education, Indiana University-Purdue University Indianapolis \\ ${ }^{3}$ School of Public Health, Indiana University \\ ${ }^{4}$ Division of Biostatistics, Indiana University
}

\begin{abstract}
Fibromyalgia (FM), defined as the presence of both chronic widespread pain and the finding of $11 / 18$ tender points on examination, is an illness associated with major personal and societal burden. Supervised aerobic exercise is an important treatment modality to improve patient symptoms. Unfortunately, adherence to an exercise regimen after a structured supervised program is disappointingly low. Since FM is a chronic illness, studies are needed to test strategies that would enhance exercise adherence in these individuals. Individuals who are able to adhere to exercise almost always maintain the symptomatic benefits of exercise. The objective of this paper was to describe the protocol of the Research to Encourage Exercise for Fibromyalgia (REEF). REEF is a randomized attention-controlled trial that seeks to test the efficacy of 6 sessions of telephone delivered motivational interviewing (MI) that targets exercise adherence to improve FM-relevant clinical outcomes (i.e., physical function and pain severity). The trial has recently completed enrolling 216 subjects, and randomization has resulted in well balanced groups. Details on the study design, MI program, and treatment fidelity are provided in the paper. Outcome assessments at week 12, week 24 and week 36 will test the immediate, intermediate and long term effects of exercise-based MI on adherence (as measured by the Community Health Activities Model Program for Seniors/CHAMPS and accelerometer) and clinical outcomes. When completed, REEF will determine whether exercise-based MI could be utilized as a management strategy to sustain the clinical benefits of exercise for FM.
\end{abstract}

\section{Keywords}

Fibromyalgia; Exercise; Physical activity; Motivational interviewing; Physical function; Pain

\footnotetext{
(C) 2010 Elsevier Inc. All rights reserved.

Address for correspondence: Dennis C. Ang, MD, MS, Assistant Professor of Medicine, Department of Medicine, 1110 West Michigan St. Room 545, Indianapolis, Indiana 46202, 317-278-6880 tel., 317-274-7792 fax., dang@iupui.edu.

Clinical trial registration: NCT00573612

Publisher's Disclaimer: This is a PDF file of an unedited manuscript that has been accepted for publication. As a service to our customers we are providing this early version of the manuscript. The manuscript will undergo copyediting, typesetting, and review of the resulting proof before it is published in its final citable form. Please note that during the production process errors may be discovered which could affect the content, and all legal disclaimers that apply to the journal pertain.
} 


\section{Introduction}

Fibromyalgia (FM) is a illness that affects at least $2 \%$ of the general population and is characterized by the presence of both chronic widespread pain (CWP) and the finding of $11 / 18$ tender points on examination[1,2]. Other than generalized pain, individuals with FM also report a substantial number of other "medically unexplained" symptoms, including fatigue, sleep disturbance, impairments in attention and other cognitive functions, irritable bowel, stiffness of muscles and joints and mood problems.

Over the last two decades, supervised exercise has been considered a major cornerstone in the management of patients with FM[3-5]. In multiple clinical trials, supervised exercise has been shown to improve symptom severity, physical function and global well-being[6-14]. Unfortunately, adherence to an exercise regimen after a structured supervised program is disappointingly low [13,15-18]. Incorporating a simple educational component to an exercise intervention does not appear to result in higher compliance with training sessions either [7,19]. After the supervised phase of an exercise program, exercise adherence declines and FM symptoms worsen [13,15-18]. Since FM is a chronic illness, studies are needed to test strategies that would maintain exercise adherence in these individuals. FM sufferers who consistently exercise are most likely to maintain initial benefits $[7,13,17,20,21]$; therefore, motivating FM patients to continue regular exercise is crucial for maintaining clinical benefits.

Miller and his colleagues [22] have developed an approach to clinician-client interactions that focuses on enhancing client's motivation to change. This approach, called motivational interviewing (MI), was initially developed to help problem drinkers cut down on or abstain from drinking alcohol. Within the principle of MI, motivation to change is viewed as something which is evoked in the patient, rather than imposed. It is a directive, clientcentered counseling style for eliciting behavior change by helping clients to explore and resolve ambivalence about a behavior (e.g., initiation and maintenance of exercise). In contrast to delivering simple advice, an MI practitioner helps a patient discuss the pros and cons of the target behavior; consequently, resolving the patient's ambivalence about the behavior.

This paper describes the protocol of the Research to Encourage Exercise for Fibromyalgia (REEF), a randomized attention-controlled trial to determine the efficacy of MI to encourage exercise (target behavior) in order to improve patient-oriented clinical outcomes (i.e., physical function and pain severity). A secondary objective of the trial is to determine the mediators between exercise-based MI intervention and improvement in clinical outcomes.

Figure 1 illustrates the conceptual model underlying REEF trial. MI will move FM patients toward the decision to adopt and/or maintain an exercise program by strengthening participants' intention- to-exercise - the final common pathway to behavior change (i.e., exercise adherence). MI will positively influence intention-to-exercise through 2 mechanisms: 1) by enabling participants to feel confident that they can exercise despite challenges (exercise self-efficacy), and 2) by tipping the balance of decisions favoring the positive features (pros) of exercise over the negative aspects (cons) of exercise (decisional balance).

\section{Methods and Design}

\subsection{Overall Study Design}

Study subjects were randomized to either the MI intervention group or the attention control (AC) group (Figure 2). The MI group received six telephone-delivered exercise-based MI 
counseling calls spread over a 12-week period. The AC group received an equal number of telephone contacts to control for attention. Outcome assessments were conducted at baseline, week 12, week 24 and week 36. To get participants started on an exercise program, all study subjects (both MI and AC groups) received two supervised exercise training sessions and an individualized exercise prescription [23] before the telephone-counseling phase of the study. The two primary endpoints were improvement in the self-report physical impairment [as measured by the Fibromyalgia Impact Questionnaire (FIQ)] at week 36 and the proportion of study subjects who increased their weekly exercise duration by $\geq 30$ minutes [as measured by Community Health Activities Model Program for Seniors (CHAMPS)] at week 36. Secondary outcomes included pain severity [assessed by the Brief Pain Inventory (BPI)], generic and FM-specific health related quality of life, the 6-minute walk test and the activity monitor (i.e., accelerometer). The study was carried out in accordance with The Code of Ethics of the World Medical Association (Declaration of Helsinki) for experiments involving humans.

\subsection{Eligibility}

All potential participants were referred from specialty or primary care clinics. Participants met the following entry criteria: (a) fulfilled the American College of Rheumatology (ACR) classification criteria for FM[1]; (b) FIQ-physical impairment score $\geq 2$; (c) average BPI pain score $\geq 4$; (d) had been on stable doses of medications for FM for $\geq 4$ weeks; (d) willingness to limit the introduction of new medications for FM; and (e) age between 18-65 years old.

Excluded were individuals with (a) known cardiovascular disease; (b) moderate-severe chronic lung disease; (c) uncontrolled hypertension; (d) orthopedic or musculoskeletal conditions that would prohibit moderate-intensity exercise; (e) active suicidal ideation; (f) planned elective surgery during the study period; (g) ongoing unresolved disability claims; (h) inflammatory rheumatic conditions (i.e. rheumatoid arthritis, systemic lupus erythematosus, and other connective tissue disease); (i) current use of medications that may affect chronotropic response to exercise (i.e. beta-blocker or calcium channel blockers); (j) pregnancy; (k) schizophrenia or other psychosis; and (1) participation in moderate-vigorous exercise for 3 days a week or more.

\subsection{Randomization}

For each eligible subject a written informed consent was requested. Eligible subjects were then randomized to one of the two treatment arms, with randomization stratified by presence of depression [Patient health assessment-8 (PHQ-8) score $\geq 15$ ], gender, and referral source (specialty vs. primary care). Allocation to treatment arm was carried out by a computergenerated randomization list with permuted block size of 2 .

\subsection{Supervised exercise training for all subjects}

At week 1 of the study timeline, each subject (both MI and AC) watched a 15-minute video on the benefits of aerobic exercise for FM. Thereafter, participants had a one-to-one consultation with a fitness instructor. The fitness instructor provided an individualized exercise prescription based on the participants' severity of symptoms and prior exercise history.

The written exercise prescription included the initial intensity, duration and frequency, as well as, the progression of the exercise regimen over the next 36 weeks. Initial exercise duration was between 10 to 12 minutes, at an intensity of 40-50\% of heart rate reserve (HRR). Using the Karvonen formula [24], the percent HRR was calculated by the following formula: $[(220-$ age $)-($ standing resting heart rate $] \times$ prescribed $\%+$ standing resting heart 
rate. For all subjects, exercise duration increased up by 1 minute each week, to a maximum of 30 minutes, where it remained for the remainder of the study. Further, exercise intensity went up by an increment of 5\% (e.g. from $40-50 \%$ to $45-55 \%$ of the HRR) every 4 weeks to attain a maximum of $65 \%$ of the HRR [25]. Exercise frequency was 2-3 times a week from week 1 to 4, 3 times a week from week 5 to 8 , and 3 to 4 times a week from week 9 till the end of the follow-up period. To ensure that participants were within their target heart rate zone, each received a strapless heart rate monitor watch.

Also during the week 1 visit, each participant received an individualized supervised exercise training session from the fitness instructor. The exercise consisted of 10 minutes of stretching and $10-12$ minutes of aerobic exercise. During the week 2 visit, the fitness instructor discussed any problems that the subject may have encountered while exercising in the past week, and then offered suggestions. On the same visit, the participants received their second individualized supervised exercise training session.

After the second supervised exercise training session, MI subjects received the phonedelivered exercise based MI counseling while the AC group received the phone-delivered education on fibromyalgia-relevant topics. Each subject had the same interventionist (MItrained health practitioner or health educator) throughout the protocol.

\subsection{Intervention}

2.5.1 Exercise-based MI counseling-MI participants had 6 telephone calls throughout the study. The phone calls were scheduled at week 3, 4, 6, 8, 10 and 12 of the study (Table 1). The MI-trained health practitioner used an MI handbook, which was successfully pilot tested in our preliminary study[26].

The telephone-delivered MI intervention was divided into 3 phases:

1. First phase: The first two calls focused on strategies that enhance motivation to exercise. It involved eliciting from the patient statements (i.e. self-motivational statements) that supported the following: a) The patient's recognition of the full nature and extent of the problem, b) The patient's concern about how he or she is currently managing the problem, c) The patient's intention of changing in the direction of adaptive pain management, specifically, graded aerobic exercise and d) The patient's optimism that changes are possible.

2. Second phase: This phase was devoted to strategies that strengthen commitment to exercise regularly and consistently. Specifically, the third call included helping the patient develop a plan for change (i.e. shift from why the patient should consider change to how the patient will make changes) communicating free choice, and reviewing consequences of graded aerobic exercise versus inactivity. The fourth phone call involved asking for a commitment to exercise and a plan worksheet.

3. Third phase: The last 2 calls were for follow-through strategies to prevent relapse of inactivity. To review the changes that have occurred since the last session, the MI-trained health practitioner praised and reinforced any and all approximations of progress. She or he also reviewed behavioral indicators of motivation, patient's responses to questions concerning reasons for making or maintaining changes, and barriers to exercise adherence. The MI-trained practitioner again obtained a commitment to follow through on the new plan.

Procedures to assure MI fidelity included the following: 1) only health professionals with significant experience conducting MI-based health coaching delivered the intervention, 2) all phone contacts were audio taped to provide ongoing feedback and coaching to the MI health practitioner, 3) MI trainers, members of the Motivational Interviewing Network of 
Trainers (MINT), provided on-going supervision and feedback to the MI health practitioner, 4) $25 \%$ of the audio taped phone contacts were formally evaluated for treatment integrity using the Motivational Interviewing Treatment Integrity (MITI) method - a focus tool to assess competence in the use of MI [27]. The MITI evaluators were blind to randomization.

2.5.2 Education attention control (AC)—Each AC call followed the same format as the MI call. During the AC call, study subjects received health information on important topics relevant to their illness. Specifically, there was one topic during each phone call that included the following: (a) overview of FM, (b) pain, (c) fatigue (d) sleep, (e) stress, and (f) living well with FM (Table 1). The AC calls were avenue to transfer relevant health information from the health educator to the study subject. The scheduled topics during each contact gave the call face validity (i.e., establish a credible pretense for the contact) while being neutral with respect to encouragement of exercise.

To ensure that the AC calls control for attention only, procedures to assure fidelity were taken. First, ongoing feedback and coaching was provided to the health educator to ensure that the phone calls remained focused on the topics included in the manual. Second, 15\% of the audio taped phone contacts were formally evaluated by one of the investigators (SM) for quality assurance. It is important to note that the health educator has no prior experience in mental health counseling in general and MI in particular. Finally, the tapes were formally evaluated using the MITI method by the same MITI evaluators. A poor evaluation on the MITI guaranteed that the $\mathrm{AC}$ was implemented appropriately.

\subsection{Outcome Measures}

Table 2 outlines the data collection protocol, including the variables that were measured and when they were assessed. Except for the 6-minute walk test and the activity monitor data, all measures were self-report and self-administered online.

\subsubsection{Primary efficacy measures}

FIQ-physical impairment (FIQ-PI): As one primary outcome measure, FIQ-PI is the 10item subscale of the Fibromyalgia Impact Questionnaire (FIQ) that inquires about the participant's ability to do 11 different types of physical activity; with each item rated on a 4point Likert-type scale. The range of the score is between 0 and 9.99, where a higher score indicates a negative impact. The FIQ-PI correlates well $(r=0.65)$ with the Arthritis Impact Measurement Scale (AIMS) lower extremity physical function scale[28]. In a trial of pool therapy and education, Mannerkorpi found the FIQ-PI to be responsive, and correlated with improvement in the 6-minute walk test[29,30].

Community Health Activities Model Program for Seniors (CHAMPS): As a co-primary outcome measure, the CHAMPS was used as a measure of exercise adherence. The CHAMPS was developed to measure physical activity change in an intervention for older adults. The CHAMPS is a 15-minute survey that asks about the frequency and duration of physical activity in a typical week of the past month. From several community-based interventions for older women and men [31-33], CHAMPS has been shown to be sensitive to change. Two-week test-retest reliability has been shown to be 0.76 and construct validity is good[34]. Correlations with activity monitors and 6-minute walk tests have been reported to range from 0.40 to 0.57 [34]. The approach is to provide a list of activities to prompt the memories of respondents. In the current study, the focused was on activities of moderate intensity or greater. The questionnaire provides measures of estimated hours per week in light, moderate and vigorously intense activities [32]. 


\subsubsection{Secondary measures}

Fibromyalgia Impact Questionnaire (FIQ): This is a reliable, validated self- assessment questionnaire widely used in clinical trials for FM[15,30,35-37]. In addition to the physical impairment subscale, it has 6 visual analog scales (VAS) for measuring sleep, pain, anxiety, morning stiffness and depression. It also measures work status, and overall well-being[28].

Brief Pain Inventory (BPI): The BPI is a pain assessment tool that has been proven reliable, valid and responsive to change among patients with chronic non-malignant pain $[38,39]$. BPI pain severity is the average of 4 items asking about worst, least, and current pain in the past week, and current level of pain.

6-minute Walk Test (6-MWT): To validate self-reported exercise activity, a 6-MWT was carried out for both the intervention and control groups. The 6-MWT is a clinically relevant aerobic endurance/fitness measure that is reproducible, sensitive to change, and significantly related to the total FIQ score in patients with FM[29,30,40,41]. To improve reliability, participants completed two trials of the 6-MWT with a 15 minute rest in between[41]. All distances were recorded in meters. From week 0 to week 36, an increase of at least 25 meters in the 6-MWT reflects exercise adherence[29,30].

Accelerometer: The GT1M ActiGraph accelerometer (or activity monitor) was used to objectively quantify the duration and intensity of physical activity in a given 7 day period. The GT1M ActiGraph is compact with a weight of 27 grams and dimensions of $3.8 \times 3.7 \times$ $1.8 \mathrm{~cm}$. In laboratory and field settings, the ActiGraph has been shown to be a valid and reliable assessment tool of physical activity[42-46]. In adults, correlation coefficients ranged from 0.66 to 0.89 between ActiGraph counts and metabolic measures[42]. In 7-15 year old boys and girls, the ActiGraph was validated against heart rate telemetry with correlation coefficients between the two ranging from $0.50-0.74[47]$. Comparisons with oxygen consumption during treadmill exercise and self-selected speed on a track found that the ActiGraph was highly related to both, and was sensitive to change in speed [48].

Importantly, the ActiGraph has been found to successfully detect bouts of moderate intensity physical activity[49]. In addition, the accelerometer has been used in various clinic populations including diabetes, obesity, chronic lung disease, chronic fatigue syndrome and FM[50-55]. The accelerometer provides measures of estimated weekly number of counts, steps and minutes of $\geq$ moderately intense physical activity. In the study, participants were required to have carried the activity monitor for at least 4 days in a week with a minimum of 10 hours each day during the waking hours. Additionally, participants were asked to clip the activity monitor on their waist (or their bra for those with higher body mass index) during each outcome assessment throughout the study.

Physical Component Summary Score (PCS): The PCS is part of the 36-item Medical Outcome Study Short-Form Health Survey (SF-36). The PCS score has been standardized to have a mean $=50, S D=10$ in the general US population. Internal consistency reliability for the PCS is $r=0.91$ with test-retest reliability $r=0.89$. Low PCS scores are indicative of poor physical functioning. The PCS includes the following subscales: physical functioning, bodily pain, role-physical and general health [56]. The SF-36 is a brief, well-established, self-administered patient questionnaire for the assessment of health status. Despite being a generic health status assessment, the SF-36 has demonstrated responsiveness to both medical [57] and non-medical interventions[29,58]. In an RCT of tramadol/acetaminophen, patients in the treatment group demonstrated improvement on physical functioning and rolephysical and bodily pain domains, as well as on the physical component summary score[36]. 


\subsubsection{Mediators}

Exercise self-efficacy (ESE): This is a 9-item scale designed to measure a person's perceptions of her confidence to engage in physical activity in various situations[59]. Response options are numbered from 0 ('not confident') to 10 ('very confident). Scoring is done by adding up the total score and dividing by the number of items [score range $=0$ to 10]. The questionnaire's validity was supported by statistically significant lambda estimates that ranged from 0.61 to 0.87 [59-61]. Further, a statistically significant relationship had been established between ESE and exercise[62-64]. The internal consistency estimate range from 0.92 to 0.95 . In two previous exercise intervention trials, ESE was shown to be responsive to change[62,63].

Decisional balance: This is a 16-item inventory assessing perceived benefits (pros) and perceived barriers (cons) to physical activity participation[65]. High scores on the 'pros' scale indicate perceptions of high benefits from exercise; high scores on the 'cons' scale indicate unfavorable perceptions of exercise and reasons not to exercise. A decisional balance index is calculated by subtracting the cons score from the pros score. A higher (or positive) decisional balance score is associated with a higher motivational readiness to exercise[65-67]. This measure has been shown to have good internal consistency: Pros $=0.90-0.95$, Cons $=0.67$ to $0.79[68,69]$. In several physical activity intervention trials, the decisional balance index was shown to be responsive to change[68-70].

Intention-to-exercise: Intention was assessed using a 3-item scale developed by Courneya and colleagues[71]. Scoring is done by adding up the item scores and dividing by the number of items [score range $=1$ to 7]. Responses to each item are averaged to provide the intention scale. This 3 -item scale has an internal consistency of 0.88 . In a pre- and post cardiac exercise rehabilitation study, the scale was shown to be sensitive to change[72]. Among cancer survivors, Courneya et al reported preexisting intention to be a predictor of exercise behavior[73].

\subsubsection{Covariates}

Patient Health Questionnaire 8-item Depression Scale (PHQ-8): PHQ-8 is a brief selfadministered scale which assesses major depressive disorder core symptoms and allows a score (range: 0 to 24) based on the total number and severity of depressive symptoms noted over the previous two-week period. Its validity and capacity to detect changes of depressive symptoms over time are well established [74-77]. A PHQ-8 score $\geq 10$ represents clinically significant depression[78].

\subsection{Statistical considerations}

\subsubsection{Sample size justification-Our 2 primary endpoints were:}

a. Improvement in physical function, as measured by the FIQ-PI, at week 36 compared to baseline. Using an alpha of 0.025 and a two-sample independent t-test, a sample size of 68 per group has $85 \%$ power to detect a minimum difference of 1.2 [29].

b. Proportion of subjects who increase their weekly exercise adherence by $\geq 30$ minutes (as measured by CHAMPS) at week 36 [16].

In a previously completed pilot study[26], the proportion of subjects at week 30 who reported $\geq 30$-minute increment of exercise time per week was 40-42\%. Using an alpha of 0.025 and a two-sample chi-square test with continuity correction, a sample size of 68 in each group has $80 \%$ power to detect a difference of $25 \%$ [40\% (MI) vs. $15 \%$ (AC)]. To adjust for multiple primary endpoints, we will use the Bonferroni-Holm method since it is 
less conservative and more powerful than the simple Bonferroni method[79]. To account for $35 \%$ attrition rate, we recruited 108 patients per group $(\mathrm{N}=216)$.

2.7.2 Statistical analyses-Baseline clinical and demographic data were compared among the two groups. Dichotomous and ordinal variables was examined using chi-square tests and continuous measures with two-sample test or two sample non-parametric Wilcoxon Rank Sum Test if the normality assumption was not met even after applying a suitable transformation. One of the two primary variables is whether a subject increases weekly exercise adherence by $\geq 30$ minutes at week 36 . However, we will also measure this outcome at weeks 12 and 24. For this dichotomous outcome, we will use a non-linear mixed-effects model. The fixed covariates will include treatment group, week and interaction term between treatment group and week. Two treatment groups will be compared at each of 12-, 24- and 36-week.The model will be fitted by the SAS procedure NLMIXED.

To compare the effect of MI intervention on the change in self-report physical function and pain severity from baseline to week 36 we will use all repeated measurements and the following mixed-effect model. We will use PROC MIXED available in SAS to fit this model. The fixed covariates will include treatment group, week and interaction term between treatment group and week. Two treatment groups will be compared at each of 12-, 24- and 36-week. Both models to analyze two primary outcomes will adjust for potential confounders if found unbalanced between two treatment groups at baseline. Intention-totreat analyses will be used for both outcomes.

To determine the mediators of MI and changes in clinical outcomes, we will use Sobel test, which is found to be more powerful than other formal methods of assessing mediation[80]. We will test the mediating effects of the following: exercise self-efficacy, decisional balance, and intention to exercise. For statistical analysis, we will use the SAS codes available in the paper by Preacher and Hayes[81].

\section{Results}

A total of 996 patients were screened for inclusion in the ongoing study. Of these, 216 (21.6\%) met the inclusion criteria, enrolled and were randomized to MI $(\mathrm{n}=107)$ and $\mathrm{AC}$ $(\mathrm{n}=109)$. The majority of screening failures were: 1$)$ exercising for 3 days a week or more $(30 \%), 2)$ medications that affects the chronotropic response to exercise $(19 \%), 3)$ age over 65 years old (11.7\%) and 4) presence of medical condition that contraindicated participation in an aerobic exercise program (11.2\%). Most of the 216 participants were female (95.8\%) and White $(88.4 \%)$. The study cohort had a mean $( \pm \mathrm{SD}$ ) age of $46 \pm 11$ years; $61 \%$ married, $78 \%$ had > high school education and 54\% were employed. At study entry, the sample had mean disease duration of $9 \pm 7$ years; $33 \%$ were on opioid analgesics; $30 \%$ were on anticonvulsant; and $62 \%$ were on an antidepressant other than tricyclics. Clinically, the mean score for FIQ-total was $67 \pm 12.7$ and FIQ-physical impairment was $5.4 \pm 1.6$, suggesting a moderate-to-severely ill patient population. For self-report pain, the mean BPI pain severity score was $6 \pm 1.3$. As measured by CHAMPS, the average weekly number of hours that subjects were engaged in $\geq$ moderate level of physical activity was $1.7 \pm 3.7$ hours per week. For the activity monitor, the average weekly number of minutes of $\geq$ moderate level of physical activity was $105.5 \pm 94.1$ minutes per week. Although the perceived benefits of exercise outweighed the perceived barriers (mean decisional balance index $=25.5 \pm 8.4$ ), the 216 participants only had moderate degree of intention to exercise (median score $=4,1^{\text {st }}$ quartile $=3$ and $3^{\text {rd }}$ quartile $=4.7$ ) at study entry. Baseline characteristics were similar across treatment groups ( $>0.2$ ) except for body mass index (Table 3). Compared to AC, subjects in the MI group were slightly heavier (32.2 \pm 7.6 vs. $30.5 \pm 6.6, \mathrm{p}=0.07$ ). 


\section{Discussion}

In the past 17 years, the FM exercise literature has largely focused on the 'specifics' (i.e. intensity, frequency, duration of exercise, pool vs. land-based exercise, etc.) of exercise that would result in clinical benefits for patients. However, patients' adherence to exercise remains problematic. The graduation from a supervised to an unsupervised environment is associated with loss of effectiveness because adherence is poor. The use of MI to maintain exercise adherence is a promising tool in sustaining clinical benefits of exercise, in terms of pain reduction and improvement in physical functioning.

Many studies have reported success with MI interventions to elicit behavior changes[82-97], but the use of MI to encourage exercise is relatively new. A recent meta-analysis showed medium effect sizes (0.53) of MI for increased physical activity in the general medical patient population[98]. MI has also been effective in increasing exercise among diabetic patients and patients with chronic heart failure[99,100]. Unlike other patient population, chronic pain patients are fearful that exercise might exacerbate their existing pain or result in a new injury or pain site, which may interfere with their planned physical exercise program $[16,17]$. Fear of pain is a potent inhibitory factor in getting patients with chronic pain into regular exercise regimens[101]. Most people need more than advice to exercise - they need assistance overcoming the barriers to exercise. Exercise-based MI may encourage patients to initiate and maintain exercise, even when such barriers as pain could provide an excuse to quit.

The principle of MI is not based on any specific theory. Rather, Miller drew from social psychology[102], cognitive dissonance[103], empathic processes from the methods of Rogers[104,105], and self-efficacy[106,107]. The Trans-theoretical Model (TTM) of behavior change emerged in parallel with MI and provided a useful framework for understanding the change process; with MI providing a mean of facilitating this change process. MI also appears to be consistent with a number of models of health behavior, such as Theory of Planned Behavior, and Social Cognitive Theory[108]. All of these models, despite differences in their terms and emphasis, share two common constructs. These are the patient's expectations about the consequences of engaging in the behavior, and the influence of the patient's perception of, or beliefs about, personal control over the behavior. The MI practitioner uses four main principles: 1. express empathy, 2 . develop discrepancy - explore the gap between future goals and current behavior, 3. roll with resistance - deflect and reframe patient statements; lessens resistance and 4. support self efficacy. The patient is seen as responsible for choosing and carrying out personal change, but at the same time he or she must have a belief in his or her ability to change.

The protocol described here has several unique features. First, the MI intervention in REEF was telephone administered and therefore has the advantage of reducing delivery cost and improving patient compliance with the program. Second, REEF consisted of only 6 sessions over a 12-week period. Weekly phone sessions then tapered off into less frequent sessions. Such a program that decreases in intensity as it advances may train the participant to continue the behavior even without the telephone calls serving as prompts or motivators. Further, a 6-session program is potentially more cost effective compared to the typical 10-12 week program. Third, the inclusion of physical activity assessment and training prior to the intervention guaranteed that participants started their exercise program well informed of the benefits and complications of exercise. REEF trial provided an exercise prescription tailored for the participant's needs and health condition. An individualized exercise prescription is especially important in FM populations as over exertion early on may sabotage further participation in an exercise program. 
REEF has successfully enrolled 216 FM patients whose baseline socio-demographic and clinical characteristics were comparable to other published non-pharmacologic clinical trials in FM[7,16,29,109]. Randomization has produced balanced groups in all variables including factors such as exercise self efficacy, decisional balance and intention to exercise. Outcome assessments at week 12 and week 36 will test the immediate and long term effects of exercise-based MI on FM-relevant clinical outcomes and exercise adherence (as measured by self-report CHAMPS and accelerometer). At the completion of this study, we expect to have a treatment approach that targets exercise adherence, which might then lead to improvements in clinical outcomes. The attractive elements of telephone communication (i.e., increased convenience of availability and access and increased time efficiency) could potentially make the MI intervention more accessible to the greater majority of FM patients. Additionally, the currently ongoing study is expected to elucidate on the mechanistic pathway of how MI impacts clinical outcomes. The knowledge gained will be important in refining future treatment approach to further sustain the benefits of exercise.

\section{Acknowledgments}

Funding/Support: National Institute of Arthritis and Musculoskeletal and Skin Diseases

Grant number: 1RO1AR054324-01A1

\section{Reference List}

1. Wolfe F, Smythe HA, Yunus MB, Bennett RM, Bombardier C, Goldenberg DL, et al. The American College of Rheumatology 1990 Criteria for the Classification of Fibromyalgia. Report of the Multicenter Criteria Committee. Arthritis Rheum 1990;33:160-172. [PubMed: 2306288]

2. Wolfe F, Ross K, Anderson J, Russell IJ, Hebert L. The prevalence and characteristics of fibromyalgia in the general population. Arthritis Rheum 1995;38:19-28. [PubMed: 7818567]

3. Goldenberg DL, Burckhardt C, Crofford L. Management of fibromyalgia syndrome. JAMA 2004;292:2388-2395. [PubMed: 15547167]

4. Sim J, Adams N. Systematic review of randomized controlled trials of nonpharmacological interventions for fibromyalgia. Clin J Pain 2002;18:324-336. [PubMed: 12218504]

5. Busch A, Schachter CL, Peloso PM, Bombardier C. Exercise for treating fibromyalgia syndrome. Cochrane Database Syst Rev 2002:CD003786. [PubMed: 12137713]

6. Buckelew SP, Conway R, Parker J, Deuser WE, Read J, Witty TE, et al. Biofeedback/relaxation training and exercise interventions for fibromyalgia: a prospective trial. Arthritis Care Res 1998;11:196-209. [PubMed: 9782811]

7. King SJ, Wessel J, Bhambhani Y, Sholter D, Maksymowych W. The effects of exercise and education, individually or combined, in women with fibromyalgia. J Rheumatol 2002;29:2620 2627. [PubMed: 12465163]

8. McCain GA, Bell DA, Mai FM, Halliday PD. A controlled study of the effects of a supervised cardiovascular fitness training program on the manifestations of primary fibromyalgia. Arthritis Rheum 1988;31:1135-1141. [PubMed: 3048273]

9. Mengshoel AM, Komnaes HB, Forre O. The effects of 20 weeks of physical fitness training in female patients with fibromyalgia. Clin Exp Rheumatol 1992;10:345-349. [PubMed: 1395219]

10. Meyer BB, Lemley KJ. Utilizing exercise to affect the symptomology of fibromyalgia: a pilot study. Med Sci Sports Exerc 2000;32:1691-1697. [PubMed: 11039639]

11. Nichols DS, Glenn TM. Effects of aerobic exercise on pain perception, affect, and level of disability in individuals with fibromyalgia. Phys Ther 1994;74:327-332. [PubMed: 8140145]

12. Norregaard J, Lykkegaard JJ, Mehlsen J, Danneskiold S. Exercise training in treatment of fibromyalgia. J Musculoskeletal Pain 1997;5:71-79.

13. Wigers SH, Stiles TC, Vogel PA. Effects of aerobic exercise versus stress management treatment in fibromyalgia. A 4.5 year prospective study. Scand J Rheumatol 1996;25:77-86. [PubMed: 8614771] 
14. Rooks DS, Gautam S, Romeling M, Cross ML, Stratigakis D, Evans B, et al. Group exercise, education, and combination self-management in women with fibromyalgia: a randomized trial. Arch Intern Med 2007;167:2192-2200. [PubMed: 17998491]

15. Bennett RM, Burckhardt CS, Clark SR, O'Reilly CA, Wiens AN, Campbell SM. Group treatment of fibromyalgia: a 6 month outpatient program. J Rheumatol 1996;23:521-528. [PubMed: 8832996]

16. Gowans SE, Dehueck A, Voss S, Richardson M. A randomized, controlled trial of exercise and education for individuals with fibromyalgia. Arthritis Care Res 1999;12:120-128. [PubMed: 10513500]

17. Gowans SE, Dehueck A, Voss S, Silaj A, Abbey SE. Six-month and one-year followup of 23 weeks of aerobic exercise for individuals with fibromyalgia. Arthritis Rheum 2004;51:890-898. [PubMed: 15593364]

18. Ramsay C, Moreland J, Ho M, Joyce S, Walker S, Pullar T. An observer-blinded comparison of supervised and unsupervised aerobic exercise regimens in fibromyalgia. Rheumatology (Oxford) 2000;39:501-505. [PubMed: 10852980]

19. van SM, Bolwijn P, Verstappen F, Bakker C, Hidding A, Houben H, et al. A randomized clinical trial comparing fitness and biofeedback training versus basic treatment in patients with fibromyalgia. J Rheumatol 2002;29:575-581. [PubMed: 11908576]

20. Lemstra M, Olszynski WP. The effectiveness of multidisciplinary rehabilitation in the treatment of fibromyalgia: a randomized controlled trial. Clin J Pain 2005;21:166-174. [PubMed: 15722810]

21. Oliver K, Cronan T. Predictors of exercise behaviors among fibromyalgia patients. Prev Med 2002;35:383-389. [PubMed: 12453716]

22. Miller, WR.; Rollnick, S. Motivational interviewing: Preparing people to change addictive behavior. Guilford Press; New York: 1991.

23. van SM, Bolwijn P, Landewe R, Verstappen F, Bakker C, Hidding A, et al. High or low intensity aerobic fitness training in fibromyalgia: does it matter? J Rheumatol 2002;29:582-587. [PubMed: 11908577]

24. KARVONEN MJ, KENTALA E, MUSTALA O. The effects of training on heart rate; a longitudinal study. Ann Med Exp Biol Fenn 1957;35:307-315. [PubMed: 13470504]

25. Fulcher KY, White PD. Randomised controlled trial of graded exercise in patients with the chronic fatigue syndrome. BMJ 1997;314:1647-1652. [PubMed: 9180065]

26. Ang D, Kesavalu R, Lydon JR, Lane KA, Bigatti S. Exercise-based motivational interviewing for female patients with fibromyalgia: a case series. Clin Rheumatol. 2007

27. Moyers TB, Martin T, Manuel JK, Hendrickson SM, Miller WR. Assessing competence in the use of motivational interviewing. J Subst Abuse Treat 2005;28:19-26. [PubMed: 15723728]

28. Burckhardt CS, Clark SR, Bennett RM. The fibromyalgia impact questionnaire: development and validation. J Rheumatol 1991;18:728-733. [PubMed: 1865419]

29. Mannerkorpi K, Nyberg B, Ahlmen M, Ekdahl C. Pool exercise combined with an education program for patients with fibromyalgia syndrome. A prospective, randomized study. J Rheumatol 2000;27:2473-2481. [PubMed: 11036846]

30. Mannerkorpi K, Ahlmen M, Ekdahl C. Six- and 24-month follow-up of pool exercise therapy and education for patients with fibromyalgia. Scand J Rheumatol 2002;31:306-310. [PubMed: 12455823]

31. King AC, Castro C, Wilcox S, Eyler AA, Sallis JF, Brownson RC. Personal and environmental factors associated with physical inactivity among different racial-ethnic groups of U.S. middleaged and older-aged women. Health Psychol 2000;19:354-364. [PubMed: 10907654]

32. Stewart AL, Mills KM, King AC, Haskell WL, Gillis D, Ritter PL. CHAMPS physical activity questionnaire for older adults: outcomes for interventions. Med Sci Sports Exerc 2001;33:11261141. [PubMed: 11445760]

33. Stewart AL, Mills KM, Sepsis PG, King AC, McLellan BY, Roitz K, et al. Evaluation of CHAMPS, a physical activity promotion program for older adults. Ann Behav Med 1997;19:353361. [PubMed: 9706362]

34. Harada ND, Chiu V, King AC, Stewart AL. An evaluation of three self-report physical activity instruments for older adults. Med Sci Sports Exerc 2001;33:962-970. [PubMed: 11404662] 
35. Goldenberg D, Mayskiy M, Mossey C, Ruthazer R, Schmid C. A randomized, double-blind crossover trial of fluoxetine and amitriptyline in the treatment of fibromyalgia. Arthritis Rheum 1996;39:1852-1859. [PubMed: 8912507]

36. Bennett RM, Kamin M, Karim R, Rosenthal N. Tramadol and acetaminophen combination tablets in the treatment of fibromyalgia pain: a double-blind, randomized, placebo-controlled study. Am J Med 2003;114:537-545. [PubMed: 12753877]

37. Burckhardt CS, Mannerkorpi K, Hedenberg L, Bjelle A. A randomized, controlled clinical trial of education and physical training for women with fibromyalgia. J Rheumatol 1994;21:714-720. [PubMed: 8035399]

38. Arnold LM, Lu Y, Crofford LJ, Wohlreich M, Detke MJ, Iyengar S, et al. A double-blind, multicenter trial comparing duloxetine with placebo in the treatment of fibromyalgia patients with or without major depressive disorder. Arthritis Rheum 2004;50:2974-2984. [PubMed: 15457467]

39. Tan G, Jensen MP, Thornby JI, Shanti BF. Validation of the Brief Pain Inventory for chronic nonmalignant pain. J Pain 2004;5:133-137. [PubMed: 15042521]

40. Pankoff B, Overend T, Lucy D, White K. Validity and responsiveness of the 6 minute walk test for people with fibromyalgia. J Rheumatol 2000;27:2666-2670. [PubMed: 11093451]

41. Pankoff BA, Overend TJ, Lucy SD, White KP. Reliability of the six-minute walk test in people with fibromyalgia. Arthritis Care Res 2000;13:291-295. [PubMed: 14635298]

42. Freedson PS, Melanson E, Sirard J. Calibration of the Computer Science and Applications, Inc. accelerometer. Med Sci Sports Exerc 1998;30:777-781. [PubMed: 9588623]

43. Sirard JR, Melanson EL, Li L, Freedson PS. Field evaluation of the Computer Science and Applications, Inc. physical activity monitor. Med Sci Sports Exerc 2000;32:695-700. [PubMed: 10731015]

44. Trost SG, Ward DS, Moorehead SM, Watson PD, Riner W, Burke JR. Validity of the computer science and applications (CSA) activity monitor in children. Med Sci Sports Exerc 1998;30:629633. [PubMed: 9565947]

45. Welk GJ, Schaben JA, Morrow JR Jr. Reliability of accelerometry-based activity monitors: a generalizability study. Med Sci Sports Exerc 2004;36:1637-1645. [PubMed: 15354049]

46. Trost SG, McIver KL, Pate RR. Conducting accelerometer-based activity assessments in fieldbased research. Med Sci Sports Exerc 2005;37:S531-S543. [PubMed: 16294116]

47. Janz KF. Validation of the CSA accelerometer for assessing children's physical activity. Med Sci Sports Exerc 1994;26:369-375. [PubMed: 8183103]

48. Nichols JF, Morgan CG, Chabot LE, Sallis JF, Calfas KJ. Assessment of physical activity with the Computer Science and Applications, Inc., accelerometer: laboratory versus field validation. Res Q Exerc Sport 2000;71:36-43. [PubMed: 10763519]

49. Masse LC, Fulton JE, Watson KL, Heesch KC, Kohl HW III, Blair SN, et al. Detecting bouts of physical activity in a field setting. Res Q Exerc Sport 1999;70:212-219. [PubMed: 10522280]

50. Kop WJ, Lyden A, Berlin AA, Ambrose K, Olsen C, Gracely RH, et al. Ambulatory monitoring of physical activity and symptoms in fibromyalgia and chronic fatigue syndrome. Arthritis Rheum 2005;52:296-303. [PubMed: 15641057]

51. Story M, Sherwood NE, Obarzanek E, Beech BM, Baranowski JC, Thompson NS, et al. Recruitment of African-American pre-adolescent girls into an obesity prevention trial: the GEMS pilot studies. Ethn Dis 2003;13:S78-S87. [PubMed: 12713213]

52. Steele BG, Belza B, Cain K, Warms C, Coppersmith J, Howard J. Bodies in motion: monitoring daily activity and exercise with motion sensors in people with chronic pulmonary disease. $\mathrm{J}$ Rehabil Res Dev 2003;40:45-58. [PubMed: 15074453]

53. Jason LA, King CP, Frankenberry EL, Jordan KM, Tryon WW, Rademaker F, et al. Chronic fatigue syndrome: assessing symptoms and activity level. J Clin Psychol 1999;55:411-424. [PubMed: 10348404]

54. Hughes AR, Gillies F, Kirk AF, Mutrie N, Hillis WS, Macintyre PD. Exercise consultation improves short-term adherence to exercise during phase IV cardiac rehabilitation: a randomized, controlled trial. J Cardiopulm Rehabil 2002;22:421-425. [PubMed: 12464830]

55. Kirk A, Mutrie N, MacIntyre P, Fisher M. Increasing physical activity in people with type 2 diabetes. Diabetes Care 2003;26:1186-1192. [PubMed: 12663595] 
56. Ware JE Jr. Sherbourne CD. The MOS 36-item short-form health survey (SF-36). I. Conceptual framework and item selection. Med Care 1992;30:473-483. [PubMed: 1593914]

57. Crofford LJ, Rowbotham MC, Mease PJ, Russell IJ, Dworkin RH, Corbin AE, et al. Pregabalin for the treatment of fibromyalgia syndrome: results of a randomized, double-blind, placebo-controlled trial. Arthritis Rheum 2005;52:1264-1273. [PubMed: 15818684]

58. Valim V, Oliveira L, Suda A, Silva L, de AM, Barros NT, et al. Aerobic fitness effects in fibromyalgia. J Rheumatol 2003;30:1060-1069. [PubMed: 12734907]

59. Resnick B, Jenkins LS. Testing the reliability and validity of the Self-Efficacy for Exercise scale. Nurs Res 2000;49:154-159. [PubMed: 10882320]

60. Resnick B, Orwig D, Zimmerman S, Hawkes W, Golden J, Werner-Bronzert M, et al. Testing of the SEE and OEE post-hip fracture. West J Nurs Res 2006;28:586-601. [PubMed: 16829639]

61. Resnick B, Luisi D, Vogel A, Junaleepa P. Reliability and validity of the self-efficacy for exercise and outcome expectations for exercise scales with minority older adults. J Nurs Meas 2004;12:235-247. [PubMed: 16138727]

62. Harnirattisai T, Johnson RA, Kawinwonggowit V. Evaluating functional activity in older Thai adults. Rehabil Nurs 2006;31:124-128. [PubMed: 16669574]

63. Harnirattisai T, Johnson RA. Effectiveness of a behavioral change intervention in Thai elders after knee replacement. Nurs Res 2005;54:97-107. [PubMed: 15778651]

64. Resnick B, Palmer MH, Jenkins LS, Spellbring AM. Path analysis of efficacy expectations and exercise behaviour in older adults. J Adv Nurs 2000;31:1309-1315. [PubMed: 10849141]

65. Marcus BH, Rakowski W, Rossi JS. Assessing motivational readiness and decision making for exercise. Health Psychol 1992;11:257-261. [PubMed: 1396494]

66. Marcus BH, Owen N. Motivational readiness, self-efficacy and decision making for exercise. Journal of applied social psychology 1992;22:3-16.

67. Marcus BH, Eaton CA, Rossi JS, Harlow LL. Self-efficacy, decision making and stage of change: an integrative model of physical exercise. Journal of applied social psychology 1994;24:489-508.

68. Pinto BM, Lynn H, Marcus BH, DePue J, Goldstein MG. Physician-based activity counseling: intervention effects on mediators of motivational readiness for physical activity. Ann Behav Med 2001;23:2-10. [PubMed: 11302351]

69. Marcus BH, Bock BC, Pinto BM, Forsyth LH, Roberts MB, Traficante RM. Efficacy of an individualized, motivationally-tailored physical activity intervention. Ann Behav Med 1998;20:174-180. [PubMed: 9989324]

70. Bock BC, Marcus BH, Pinto BM, Forsyth LH. Maintenance of physical activity following an individualized motivationally tailored intervention. Ann Behav Med 2001;23:79-87. [PubMed: 11394558]

71. Courneya KS. Understanding readiness for regular physical activity in older individuals: an application of the theory of planned behavior. Health Psychol 1995;14:80-87. [PubMed: 7737078]

72. Blanchard CM, Courneya KS, Rodgers WM. Determinants of exercise intention and behavior during and after phase 2 cardiac rehabilitation: an application of the theory of planned behavior. Rehabilitation Psychology 2002;47:308-323.

73. Courneya KS, Friedenreich CM, Sela RA, Quinney HA, Rhodes RE. Correlates of adherence and contamination in a randomized controlled trial of exercise in cancer survivors: an application of the theory of planned behavior and the five factor model of personality. Ann Behav Med 2002;24:257-268. [PubMed: 12434937]

74. Lowe B, Unutzer J, Callahan CM, Perkins AJ, Kroenke K. Monitoring depression treatment outcomes with the patient health questionnaire-9. Med Care 2004;42:1194-1201. [PubMed: 15550799]

75. Lowe B, Kroenke K, Herzog W, Grafe K. Measuring depression outcome with a brief self-report instrument: sensitivity to change of the Patient Health Questionnaire (PHQ-9). J Affect Disord 2004;81:61-66. [PubMed: 15183601]

76. Kroenke K, Spitzer RL, Williams JB. The PHQ-9: validity of a brief depression severity measure. J Gen Intern Med 2001;16:606-613. [PubMed: 11556941] 
77. Lowe B, Spitzer RL, Grafe K, Kroenke K, Quenter A, Zipfel S, et al. Comparative validity of three screening questionnaires for DSM-IV depressive disorders and physicians' diagnoses. J Affect Disord 2004;78:131-140. [PubMed: 14706723]

78. Kroenke K, Spitzer RL. The PHQ-9: A new depression diagnostic and severity measure. Psychiatric annals 2002;32:1-7.

79. Holm S. A simple sequentially rejective multiple test procedure. Scandinavian Journal of Statistics 1979;6:65-70.

80. Sobel, ME. Asymptotic confidence intervals for indirect effects in structural equation models. In: Leinhardt, S., editor. Sociological methodology. American Sociological Association; Washington, DC: 1982. p. 290-310.

81. Preacher KJ, Hayes AF. SPSS and SAS procedures for estimating indirect effects in simple mediation models. Behav Res Methods Instrum Comput 2004;36:717-731. [PubMed: 15641418]

82. Tappin DM, Lumsden MA, Gilmour WH, Crawford F, McIntyre D, Stone DH, et al. Randomised controlled trial of home based motivational interviewing by midwives to help pregnant smokers quit or cut down. BMJ 2005;331:373-377. [PubMed: 16096304]

83. Colby SM, Monti PM, O'Leary TT, Barnett NP, Spirito A, Rohsenow DJ, et al. Brief motivational intervention for adolescent smokers in medical settings. Addict Behav 2005;30:865-874. [PubMed: 15893085]

84. McCambridge J, Strang J. Deterioration over time in effect of Motivational Interviewing in reducing drug consumption and related risk among young people. Addiction 2005;100:470-478. [PubMed: 15784061]

85. Samet JH, Horton NJ, Meli S, Dukes K, Tripps T, Sullivan L, et al. A randomized controlled trial to enhance antiretroviral therapy adherence in patients with a history of alcohol problems. Antivir Ther 2005;10:83-93. [PubMed: 15751766]

86. Wakefield M, Olver I, Whitford H, Rosenfeld E. Motivational interviewing as a smoking cessation intervention for patients with cancer: randomized controlled trial. Nurs Res 2004;53:396-405. [PubMed: 15586136]

87. Robles RR, Reyes JC, Colon HM, Sahai H, Marrero CA, Matos TD, et al. Effects of combined counseling and case management to reduce HIV risk behaviors among Hispanic drug injectors in Puerto Rico: a randomized controlled study. J Subst Abuse Treat 2004;27:145-152. [PubMed: 15450647]

88. Kavanagh DJ, Young R, White A, Saunders JB, Wallis J, Shockley N, et al. A brief motivational intervention for substance misuse in recent-onset psychosis. Drug Alcohol Rev 2004;23:151-155. [PubMed: 15370020]

89. Steinberg ML, Ziedonis DM, Krejci JA, Brandon TH. Motivational interviewing with personalized feedback: a brief intervention for motivating smokers with schizophrenia to seek treatment for tobacco dependence. J Consult Clin Psychol 2004;72:723-728. [PubMed: 15301657]

90. Mullins SM, Suarez M, Ondersma SJ, Page MC. The impact of motivational interviewing on substance abuse treatment retention: a randomized control trial of women involved with child welfare. J Subst Abuse Treat 2004;27:51-58. [PubMed: 15223094]

91. McCambridge J, Strang J. The efficacy of single-session motivational interviewing in reducing drug consumption and perceptions of drug-related risk and harm among young people: results from a multi-site cluster randomized trial. Addiction 2004;99:39-52. [PubMed: 14678061]

92. Miller WR, Yahne CE, Tonigan JS. Motivational interviewing in drug abuse services: a randomized trial. J Consult Clin Psychol 2003;71:754-763. [PubMed: 12924680]

93. Graeber DA, Moyers TB, Griffith G, Guajardo E, Tonigan S. A pilot study comparing motivational interviewing and an educational intervention in patients with schizophrenia and alcohol use disorders. Community Ment Health J 2003;39:189-202. [PubMed: 12836801]

94. Baker A, Lewin T, Reichler H, Clancy R, Carr V, Garrett R, et al. Evaluation of a motivational interview for substance use within psychiatric in-patient services. Addiction 2002;97:1329-1337. [PubMed: 12359037]

95. Carroll KM, Libby B, Sheehan J, Hyland N. Motivational interviewing to enhance treatment initiation in substance abusers: an effectiveness study. Am J Addict 2001;10:335-339. [PubMed: 11783748] 
96. Stotts AL, Schmitz JM, Rhoades HM, Grabowski J. Motivational interviewing with cocainedependent patients: a pilot study. J Consult Clin Psychol 2001;69:858-862. [PubMed: 11680565]

97. Colby SM, Monti PM, Barnett NP, Rohsenow DJ, Weissman K, Spirito A, et al. Brief motivational interviewing in a hospital setting for adolescent smoking: a preliminary study. J Consult Clin Psychol 1998;66:574-578. [PubMed: 9642898]

98. Burke BL, Arkowitz H, Menchola M. The efficacy of motivational interviewing: a meta-analysis of controlled clinical trials. J Consult Clin Psychol 2003;71:843-861. [PubMed: 14516234]

99. Brodie DA, Inoue A. Motivational interviewing to promote physical activity for people with chronic heart failure. J Adv Nurs 2005;50:518-527. [PubMed: 15882368]

100. Smith DE, Heckemeyer CM, Kratt PP, Mason DA. Motivational interviewing to improve adherence to a behavioral weight-control program for older obese women with NIDDM. A pilot study. Diabetes Care 1997;20:52-54. [PubMed: 9028693]

101. Vlaeyen JW, Linton SJ. Fear-avoidance and its consequences in chronic musculoskeletal pain: a state of the art. Pain 2000;85:317-332. [PubMed: 10781906]

102. Miller WR. Motivational interviewing with problem drinkers. Behav Psychother 1983;11:172.

103. Festinger, L. A theory of cognitive dissonance. Stanford University Press; Stanford CA: 1957.

104. ROGERS CR. The necessary and sufficient conditions of therapeutic personality change. J Consult Psychol 1957;21:95-103. [PubMed: 13416422]

105. Rogers, CR. A theory of therapy, personality and interpersonal relationships as developed in the client-centred framework. In: Koch, S., editor. Psychology: the study of science. Formulations of the person and the social context. McGraw-Hill; New York: 1959. p. 184-256.

106. Bandura A. Self-efficacy mechanism in human agency. Am Psychol 1982;37:122-147.

107. Bandura A. Self-efficacy: toward a unifying theory of behavioral change. Psychol Rev 1977;84:191-215. [PubMed: 847061]

108. Britt E, Hudson SM, Blampied NM. Motivational interviewing in health settings: a review. Patient Educ Couns 2004;53:147-155. [PubMed: 15140454]

109. Da CD, Abrahamowicz M, Lowensteyn I, Bernatsky S, Dritsa M, Fitzcharles MA, et al. A randomized clinical trial of an individualized home-based exercise programme for women with fibromyalgia. Rheumatology (Oxford) 2005;44:1422-1427. [PubMed: 16030079] 
Intervention

Motivational Interviewing

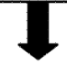

Mediators

1. Exercise self-efficacy

2. Decisional balance

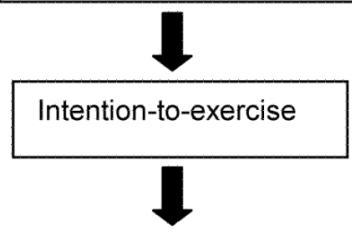

Behavior

Exercise adherence

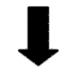

Clinical outcomes

1. Physical function

2. Pain

Figure 1.

Conceptual Model Underlying REEF Trial 


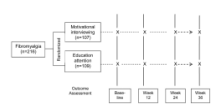

Figure 2.

Schematic overview of the REEF study design 
Table 1

Intervention Schedule

\begin{tabular}{|c|c|c|}
\hline Study timeline & Motivational Interviewing (MI) & Attention-control (AC) \\
\hline Week 1: Visit 1 & \multicolumn{2}{|c|}{ 2. Watch video: FM and benefits of exercise } \\
\hline & \multicolumn{2}{|c|}{$\begin{array}{l}\text { 3. Individualized exercise prescription and } \\
\text { supervision }\end{array}$} \\
\hline Week 2: Visit 2 & \multicolumn{2}{|c|}{ 1. Review of exercise prescription } \\
\hline & \multicolumn{2}{|c|}{ 2. Individualized exercise supervision } \\
\hline $\begin{array}{l}\text { Week 3: Phone } \\
\text { session } 1\end{array}$ & Self-motivational statements & Overview of FM \\
\hline $\begin{array}{l}\text { Week 4: Phone } \\
\text { session } 2\end{array}$ & $\begin{array}{l}\text { Optimism about change and } \\
\text { intention to change }\end{array}$ & Pain * \\
\hline $\begin{array}{l}\text { Week 6: Phone } \\
\text { session } 3\end{array}$ & Communicating free choices & Fatigue \\
\hline $\begin{array}{l}\text { Week 8: Phone } \\
\text { session } 4\end{array}$ & Commitment to exercise & Sleep \\
\hline $\begin{array}{l}\text { Week 10:Phone } \\
\text { session } 5\end{array}$ & $\begin{array}{l}\text { Reinforce any approximation } \\
\text { of progress \& review reasons } \\
\text { for maintaining changes }\end{array}$ & Stress \\
\hline $\begin{array}{l}\text { Week 12: Phone } \\
\text { session } 6\end{array}$ & Barriers to exercise adherence & Living well with FM \\
\hline
\end{tabular}




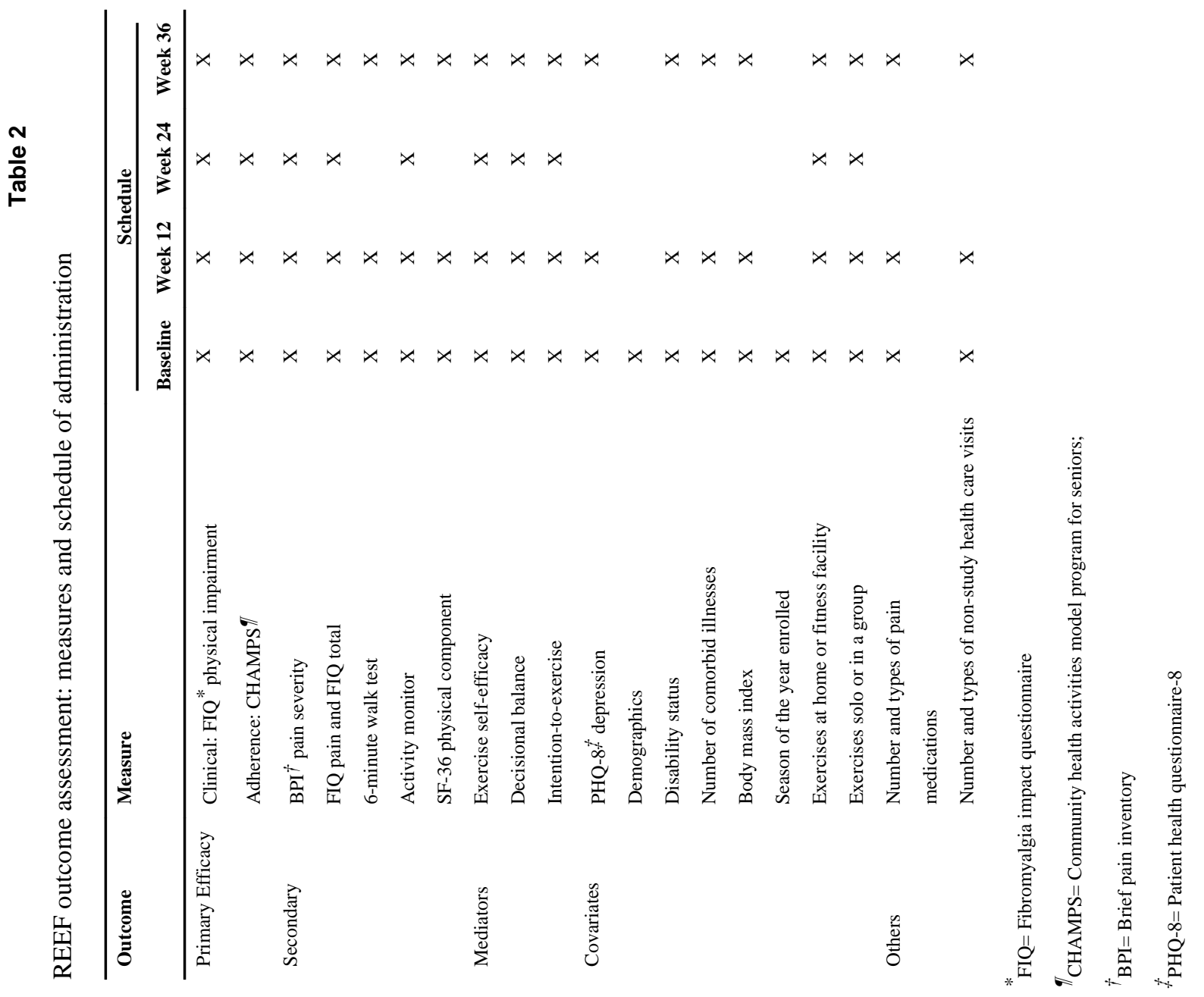


Table 3

Baseline characteristics of 216 subjects enrolled in the REEF study

\begin{tabular}{|c|c|c|}
\hline & $\begin{array}{l}\text { Motivational } \\
\text { interviewing } \\
\quad(\mathbf{n}=107)\end{array}$ & $\begin{array}{c}\text { Education } \\
\text { attention } \\
\text { control } \\
(\mathbf{n}=109)\end{array}$ \\
\hline Age in years, mean (SD) & $46.0(11.4)$ & $45.7(11.0)$ \\
\hline Gender, \% female & 96.3 & 95.4 \\
\hline Ethnicity, \% non-Hispanic & 99.1 & 98.2 \\
\hline Race, $\%$ white & 90.7 & 86.2 \\
\hline Education, $\%>$ high school & 76.6 & 78.9 \\
\hline Marital status, $\%$ married & 57.9 & 64.2 \\
\hline Employment, \% employed & 57.9 & 49.5 \\
\hline Body mass index, mean (SD) & $32.3(7.6)$ & $30.5(6.6)$ \\
\hline $\begin{array}{l}\text { Duration of fibromyalgia diagnosis in years, mean } \\
\text { (SD) }\end{array}$ & $8.9(6.4)$ & $9.1(7.6)$ \\
\hline PHQ-8 depression (range 0-24), mean (SD) & $12.4(4.8)$ & $12.7(5.1)$ \\
\hline BPI pain intensity (range $0-10$ ), mean (SD) & $5.9(1.2)$ & $6.0(1.4)$ \\
\hline FIQ-physical impairment (range 0-10), mean (SD) & $5.3(1.5)$ & $5.4(1.7)$ \\
\hline FIQ total (range 0-100), mean (SD) & $67.5(12.0)$ & $66.6(13.5)$ \\
\hline Exercise self-efficacy (range 0-10), mean (SD) & $5.4(1.9)$ & $5.3(2.0)$ \\
\hline $\begin{array}{l}\text { Decisional balance: benefit-barrier (range -20 - 44), } \\
\text { mean (SD) }\end{array}$ & $26.0(8.7)$ & $25.0(8.2)$ \\
\hline Intention to exercise, (range 1-7) ${ }^{\dagger}$ & $4(2.7,4.7)$ & $4(3.0,4.7)$ \\
\hline $\begin{array}{l}\text { Medications, \% } \\
\text { prescribed Non-tricyclic } \\
\text { antidepressants } \\
\text { Anticonvulsants } \\
\text { Opioid analgesics }\end{array}$ & $\begin{array}{l}66.4 \\
31.8 \\
32.7\end{array}$ & $\begin{array}{l}57.8 \\
27.5 \\
33.0\end{array}$ \\
\hline $\begin{array}{l}\text { CHAMPS, mean (SD) Light only (hrs/wk) } \\
\text { Moderate only (hrs/wk) } \\
\text { Vigorous only (hrs/wk) }\end{array}$ & $\begin{array}{l}4.9(4.4) \\
1.4(2.4) \\
0.1(0.8)\end{array}$ & $\begin{array}{l}5.2(5.0) \\
1.7(4.1) \\
0.2(0.7)\end{array}$ \\
\hline $\begin{array}{l}\text { Activity monitor, mean } \\
(\mathrm{SD}) \text { Counts/wk } \times 10^{4} \\
\text { Steps/wk } \times 10^{4} \\
\text { Min/wk of } \geq \text { moderate activity }\end{array}$ & $\begin{array}{l}125.0(55.5) \\
2.9(1.2) \\
99(86)\end{array}$ & $\begin{array}{l}133.3(62.4) \\
2.9(1.1) \\
112(101)\end{array}$ \\
\hline Meters walked in 6 minutes, mean $(\mathrm{SD})$ & $479.5(75.5)$ & $486.5(84.7)$ \\
\hline
\end{tabular}

Abbreviations: PHQ-8 = Patient Health Questionnaire-8; BPI = Brief Pain Inventory; FIQ = Fibromyalgia Impact Questionnaire; CHAMPS = Community Health Activities Model Program for Seniors; $\mathrm{n}=$ number of patients; $\mathrm{SD}=$ standard deviation.

Note: For PHQ-8, BPI and FIQ scales, a higher score indicates a worse state of health.

${ }^{\dagger}$ Median score $\left(1^{\text {st }}, 3^{\text {rd }}\right.$ quartiles).

F Average of two 6-minute walk tests. 